\title{
Pensions and social inclusion in an ageing China
}

\author{
HUOYUN ZHU* and ALAN WALKER $\dagger$
}

\begin{abstract}
The inclusive development strategy proposed by the Chinese government embraces social inclusion for older people. In line with most developing countries, China's policy on social inclusion for older people focuses almost exclusively on material security in the form of pensions. This paper examines the impact of pensions on social inclusion for older people across four dimensions: family interaction, social support, social participation and self-assessment using data from the 2014 China Longitudinal Ageing Social Survey. The results demonstrate that pensions improve dramatically the relationships between older adults and their family members and friends, and therefore their social inclusion in the life world. The exception is social participation which seems to be immune to material income effects. However, the stratified pension system in China generates complex and hierarchical effects on social inclusion among different sub-groups. Social inclusion among older people with high exclusion risks but low pensions is very sensitive to pension levels. Conversely, most pensions are distributed to those with the lowest exclusion risks as a result of the disappearance of their impact on social inclusion. We argue that future social inclusion policies for older people in China should focus first on achieving greater equality in pensions.
\end{abstract}

KEY WORDS - ageing, social exclusion, social inclusion, pension, China.

\section{Introduction}

Inclusive development has been rooted in the idea of universal human rights since the 1940s and was reflected in the United Nations Agenda 21 as well as the Millennium Development Goals. In contrast to sustainable development, which mainly focuses on economic and environmental aspects, inclusive development emphasises the social dimension (Gupta,

* School of Public Management, Nanchang University, China.

$\dagger$ Department of Sociological Studies, The University of Sheffield, UK. 
Pouw and Ros-Tonen 2015) which first appeared in publications of the Asian Development Bank as a strategy towards empowerment and equity, based on poverty elimination, human and social capital development, gender equality and social protection (Rauniyar and Kanbur 2010). In China, inclusive development was proposed by the former party Chair, $\mathrm{Hu}$ Jintao, at the Boao Forum for Asia in 2011, and indicated a major shift of ideology from regarding economic growth as the central task to a focus on all-round development (Gao 2012). This change reflected the global transition of economic development into a 'new normal' characterised by economic slowdown accompanied by the growth of social problems such as income inequality and social exclusion ( $\mathrm{Li}$ and Zhang 2014; Xiang 2014).

Inclusive development should, by definition, embrace older people even if the rhetoric of economic growth focuses mainly on those of working age. Both developed and developing countries have been experiencing a dramatic ageing of their populations. The report World Population Ageing 2013 put the number of older persons at 841 million, with a projected increase to 2 billion in $205^{\circ}$ (United Nations 2013). Older people are one of the groups most vulnerable to exclusion because of their likelihood of physical frailty, loss of paid work, reduction in participation in various domains of life as well as age discrimination (Brocklehurst and Laurenson 2008; Feng 2011). China not only has the largest population in the world but also the largest number of older persons. The country experienced two baby booms in the 2oth century, which will lead to two ageing peaks between 2010 and 2030 as a result of the addition of more than 160 million older persons (Chen 1999). The rate of population ageing has already accelerated and is projected to reach 32.8 per cent in $205^{\mathrm{O}}$ and 34.3 per cent in 2100 . The numbers aged 60 and over will exceed 454 million in $205^{\circ}$ and 372 million in 2100 (United Nations 2012). The huge and urgent needs of older people in China challenge the country's social security system as well as all support providers, especially in terms of family and government. According to the China Health and Retirement Longitudinal Study 2015 report, one-third of Chinese people aged 60 and over have severe depression, and the prevalence of hypertension and diabetes is 53.6 and 23.9 per cent, respectively (Lancet 2016).

For practical social policy purposes, inclusive development can be roughly translated into social inclusion. In respect of the older population, it can be understood globally as the elimination of poverty, where individuals have equal access to the social security and enjoy a decent standard of living, the elimination of stereotypes and barriers to social participation, intergenerational solidarity and the sharing of the benefits of socio-economic development ( $\mathrm{Du} 2013$ ). In response to the ageing of the population and 
the goal of inclusive development, over 30 polices have been published by different government departments in China, over the past decade, with the aim of promoting income security and social services for older people $(\mathrm{Li}$, Zhang and Chen 2015). For example, the implementation of the New Rural Social Pension (NRSP) in 2009, covering rural residents; and the Urban Resident Social Pension in 2011, covering those urban residents exempted from other pension systems; and the reform of the Government and Institution Pensions (GIP) in 2014 with the aim of greater social equality. Together these measures have established basic income security for older people in China, a remarkable feat by any standards of social policy (Zhu and Walker 2017).

In line with most developing countries, policy for older people in China almost exclusively focuses on income provision such as pensions, which reflects an assumption that when financial risks are addressed other domains of wellbeing will follow suit (Lloyd-Sherlock 2010). Although income welfare alone does not capture all aspects of human wellbeing, especially in terms of subjective satisfaction particularly when looking at changes over time or in individual status through the lifecourse (Easterlin 2010; Copestake and Camfield 2010), many studies argue that pension benefits have significant positive impacts on poverty reduction, human development, the social status of older people within their households and communities, later life health and mortality (Norström and Palme 2010) and overall levels of satisfaction with individual and household wellbeing (Bender 2012; Esser and Palme 2010; Lloyd-Sherlock, Saboia and Ramírez-Rodríguez 2012; Panis 2004). Thus, it is important to explore the complex relationship between pensions and wellbeing of older people in the context of inclusive development and social inclusion in China. This is the main aim of this paper. The first part very briefly introduces the relevant literature with respect to social exclusion and inclusion in later life. The following section describes the study design and data-set as well as the methodology. The third part focuses on assessing empirical evidence on the relationship between pensions and social inclusion in later life based on the 2014 China Longitudinal Ageing Social Survey (CLASS). The paper concludes by identifying policy lessons for China and other developing countries.

\section{Social exclusion and ageing}

The concept of social exclusion first emerged in France in the 1960 primarily referring to the poor. As successive social and political crises erupted in France during the 1980s, social exclusion came to be applied 


\section{Huoyun Zhu and Alan Walker}

to more and more types of social disadvantages and encompassed new social groups and problems (Silver 1994). Differing from operational definitions from governments, scientific approaches have sought to move beyond the identification of problems, and probe the ways in which individuals and groups are cut off from mainstream society. For example, Walker and Walker (1997: 8) defined social exclusion as a 'dynamic process of being shut out, fully or partially, from any of the social, economic, political and cultural systems which determine the social integration of a person in society'. Levitas, Pantazis and Fahmy (2007: 25) defined it as 'the lack or denial of resources, rights, goods and services, and the inability to participate in the normal relationships and activities to the majority of people in a society'. In practice, although, it is impossible to find a single definition of exclusion, both researchers and policy makers all agree on one point, social exclusion is a multi-dimensional and dynamic conception representing both an outcome and an array of social processes (Byrne 2005). Multi-dimensional social exclusion is commonly conceptualised in relation to two main dimensions: economic-structural exclusion and social-cultural exclusion. The former dimension can be further divided into material deprivation and social rights, while the latter is composed of social participation and normative integration (Jehoel-Gijsbers and Vrooman 2007). In a similar vein, Burchardt, Le Grand and Piachaud (2002) identified four dimensions in which people may be regarded as social excluded: consumption (the capacity to purchase goods and services); production (participation in economically or socially valuable activities); political engagement (involvement in local or national decision-making); and social interaction (integration with family, friends and community). Social exclusion also varies in meaning according to ideological and cultural contexts. Silver (1994) initiated a threefold typology of the multiple meanings of exclusion based on different theoretical perspectives, political ideologies and national discourses: solidarity, specialisation and monopoly. A range of recent studies propose the idea of cumulative advantage and disadvantage across the lifecourse, changing over time and potentially extending their reach from one generation to the next (Baars et al. 2006; Dannefer 2003; O'Rand $2002)$.

The voluminous literature on social exclusion treats it and inclusion as essentially two sides of the same coin: the one side being the problem and the other the solution. This is clearly rather simplistic because social inclusion, like exclusion, is a relative status which may be assessed by its degree, but also it is uniquely a positive 'plea for change in the principles by which resources are distributed, in the arrangements which govern access to organisations, institutions and social relations, and in social attitudes' (Walker and Walker 2012: 182). Thus, in this paper we have attempted to 
operationalise the idea of social inclusion, at least to the extent that the available data will allow, while being mindful that the dominant academic and policy discourses are conducted mainly in terms of social exclusion.

The definitions discussed above have been applied to tackle social exclusion among various population groups such as the disabled, abused children, single parents and the mentally ill. In recent years researchers have paid closer attention to social exclusion in relation to the older population and its special features (Lui et al. 2011; Walker et al. 2006; Warburton, $\mathrm{Ng}$ and Shardlow 2013). There are two key concerns that need to be addressed when adopting an exclusion focus on older adults. The first is the ways in which exclusion in later life might differ from that at earlier stages of the lifecourse; the second is a concern to identify the prime drivers of exclusion in later life (Scharf and Keating 2012). As for the first concern, researchers in recent years have identified characteristics of social exclusion that are especially relevant for older people, such as persistent poverty, limited access to community services and an inability to engage in civic activities. In the absence of a single agreed definition referring to the exclusion of older people, the United Kingdom (UK) Social Exclusion Unit (2006) presented a shorthand definition: an experience characterised by deprivation and the lack of access to social networks, activities and services that results in a poor quality of life. Based on the English Longitudinal Study of Ageing (ELSA), Walker et al. (2006) constructed social exclusion measurement indicators with seven dimensions for older people: social relationships, cultural and leisure activities, civic activities, basic services, neighbourhood, financial products and material goods. Scharf, Phillipson and Smith (2005) identified five domains of social exclusion of older people: material resources, social relations, civic activities, basic services and neighbourhood exclusion. Furthermore, cumulative social disadvantages, age-related characteristics and age discrimination (Social Exclusion Unit 2006), as well as non-age-friendly communities (Phillipson and Scharf 2004; Scharlach and Lehning 2013) coupled with deprived inner-city areas (Buffel, Phillipson and Scharf 2013; Burns, Lavoie and Rose 2012), contribute to the unique nature of the exclusion of older adults.

In the process of exploring the reasons triggering the problem of exclusion in later life, the early 'acquiescent functionalist' accounts of social exclusion in old age took as their starting point individual adjustment to ageing, retirement or physical decrescence (Cumming and Henry 1961) and ignored the social structural influences. While individual physical and mental health does commonly deteriorate in late old age, the marginalisation and dependency of older people could more properly be viewed as 'socially created', a product of forced exclusion from work, poverty, 


\section{Huoyun Zhu and Alan Walker}

institutionalisation and passive forms of community care (Townsend 1981; Walker 1980, 1981; Walker, Sinfield and Walker 2011). Social exclusion created by social policy caused divisions both between older people and the rest of the population and between different groups of older people. On the one hand, 'old' age is socially defined as the statutory pension age which artificially enforces workers to withdraw from the labour market regardless of their individual will and health status, and which not only reduces their income, but also reduces their range of social contacts (Walker 1981). Although less blatant in those countries under the European Union (EU) Equal Treatment Directive, older workers are none the less still often encouraged to exit from the labour market. On the other hand, social exclusion among older people is a function of low economic and social status prior to retirement. For example, cross-national research revealed that in the UK as well as the United States of America (USA), older people with higher incomes prior to retirement were less likely than the lower-income ones to rely solely on the state pension, while more likely to also receive private and occupational pensions (Walker 1981, 2009), which resulted in 'two nations' in old age (Titmuss 1955). Subsequent critical gerontology research has shown the gendered nature of this distribution of pension rights and benefits and the vastly unequal access of different minority ethnic groups (Arber and Ginn 1991; Nazroo et al. 2004).

\section{Pensions and social inclusion for older people}

As HelpAge International (2000) has argued, poverty and social exclusion remain the main stumbling blocks to the realisation of the human rights of older people. Pensions are essential for older people to fill the income gap caused by exclusion from access to paid employment although that also creates new inequalities. For most older people, the receipt of state transfers in the form of a pension, as well as pensions from employers and the market, are essential to escape poverty. Up to now, the broad majority of countries ( 166 out of 178 countries for which information is available) provide contributory or non-contributory pensions (International Labour Organization 2014). In Organisation for Economic Co-operation and Development countries, 59 per cent of the household incomes of men and women aged $6_{5}$ and over come from public pension transfers, the proportion of which is about 60 per cent in the majority of European countries. The prominent role of pensions lies in poverty reduction, while at the heart of attempts to achieve social inclusion through age-related changes is a concern with income poverty. Since 1966 , the poverty rate of older people aged $6_{5}$ and over in the USA has 
decreased dramatically in contrast to the increase among the rest of the population (Fontenot, Renwick and Housing Statistics Division 2016). Even in the era of financial crisis from $2007 / 08$, the poverty rate among older people in the EU decreased steadily, as a result of the safety net provided by pensions, while the poverty rate among the rest of the population, such as children, young people and working-age adults, increased (Zaidi and Antczak 2016). For example, the EU population aged $6_{5}$ and over grew by 6.5 million from 2008 to 2014 , while the poverty rate of older people was 17.7 per cent in 2014, 6 per cent lower than in 2008. In the UK, the poverty rate among pensioners declined from a peak of 43 per cent in 1989 to 17 per cent in 2011 , being lower than those for the working-age population and children (Cribb et al. 2013). The ELSA indicated that only one-quarter of women and one-third of men aged $6_{5}$ and over successfully escape from poverty without public pensions, which plays a mediating role offsetting the disadvantages of employment and family history in the lifecourse (Price et al. 2016). In developing countries, the impact of pensions on poverty reduction is almost entirely due to social pensions, also called tax-financed pensions, which are non-contributory pensions financed by the public purse. Given the limited financial affordability and low coverage of contributory pensions, the social pension is an optimal instrument to respond to old-age poverty (Pestieau, Dethier and Ali 2011 ). The prevalence of social pensions has been shown to be critical in poverty reduction in Latin America both for individual older people and their family members (Bertranou and Grushka 2002; Bertranou, Van Ginneken and Solorio 2004), Africa (Bello et al. 2008; Dhemba 2013; Kakwani and Subbarao 2007) and Asia (Barrientos 2015; Handayani and Babajanian 2012).

In addition to direct poverty reduction, pensions also promote mental health and non-material wellbeing, subsequently promoting social inclusion for older people. Dramatically decreased mortality rates within democratic welfare states in the past century have been attributed to economic growth and the expansion of social welfare (Kangas 2010). More generous pensions enable older people and their families to access health resources. Better health was found in 13 Western European countries with more generous pensions, and the 'basic pension' being less related to a person's work history was better than 'income security' for older persons' health (Esser and Palme 2010) as well as low mortality (Norström and Palme 2010). Pensions also contribute to positive social impacts, particularly in terms of cultivating social capital for older people, and enhance their status in households and communities. For example, older people use pensions to maintain connections and social networks within their communities by making donations and contributions as socially required for marriages, funerals 


\section{Huoyun Zhu and Alan Walker}

and religions (Suwanrada and Wesumperuma 2012). The positive impact of pensions both on material, physical, mental and social dimensions are reflected in subjective wellbeing and life satisfaction. The positive relationship between income and subjective wellbeing has been demonstrated already both at individual and state levels (Diener, Tay and Oishi 2012; Okulicz-Kozaryn 2012).

\section{Theoretical framework, data and methods}

\section{Theoretical framework}

As with the concept of social exclusion, the idea of social inclusion is multidimensional. The World Health Organization's (WHO) active ageing approach provides a conceptual framework and practical programme aimed at achieving social inclusion (WHO 2002). The term 'active' refers to continuing participation in social, economic, cultural, spiritual and civic affairs, not just the ability to be physical active or to participate in the labour force (WHO 2002). Based on this approach, the European Commission's Directorate General of Employment, Social Affairs and Inclusion and the Population Unit of the United Nations Economic Commission for Europe initiated the Active Ageing Index (AAI) in 2012 to quantitatively monitor the outcome of active ageing policies at different levels. The AAI comprises four dimensions: employment, participation, independent healthy and secure living, and capacity and enabling environment for active ageing, which gave us an important reference point for this paper. However, due to limitations of data availability, we cannot apply the AAI in China. Also this paper aims to explore the correlation between pensions and social exclusion rather than assessing the level of AAI. The notion of social inclusion in this paper is operationalised using four dimensions: self-assessment of overall social inclusion, familial interaction, social support and public participation. Many specific sub-groups, such as the widowed, unmarried, divorced and separated older women, are the more likely to face multiple disadvantage and multiple exclusion (Walker 1981). Although Walker et al. (2006) did not find a simple domino effect among different forms of exclusion, where exclusion in one area appears to cause exclusion in another and so on, we can examine inversely the possible domino effect of pension policy on social inclusion. For example, the positive effect of pensions on harmonious familial relationships between older people and their children may promote their enthusiasm for public participation which would then improve their self-assessment of their degree of social inclusion. In the context of a traditional culture in China, interaction with children is prior to any other 


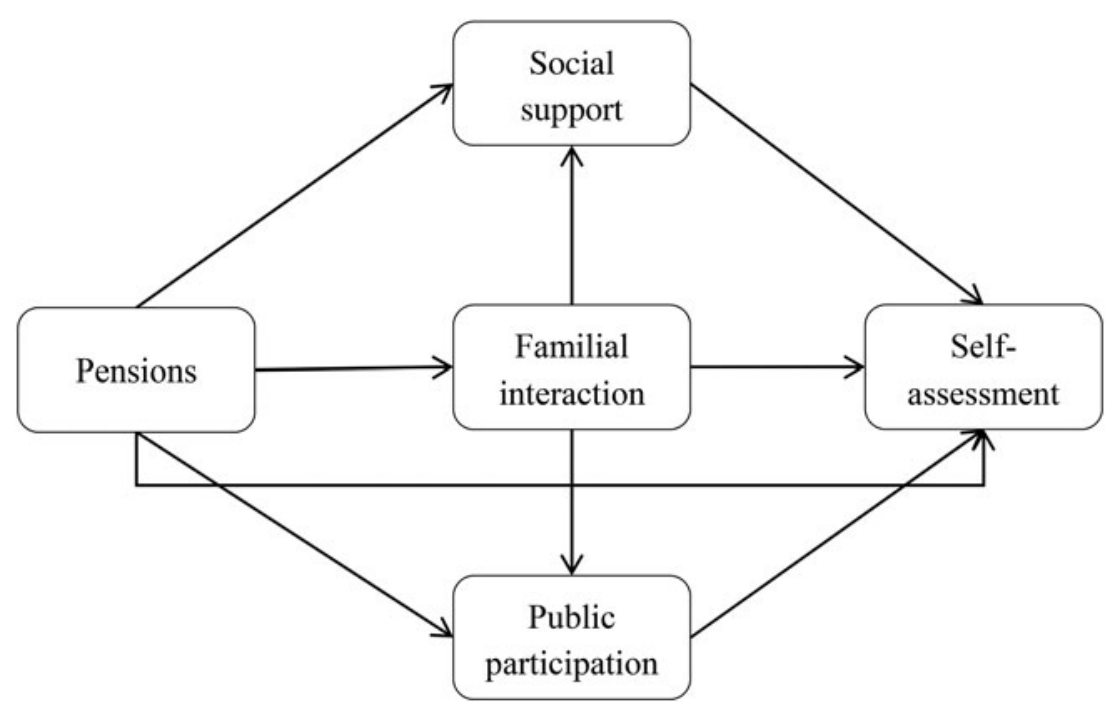

Figure 1. Theoretical framework.

social activities for older people, thus we set familial interaction as an important intervening variable between pensions and variables of social support and public participation. Self-assessment of social inclusion is mainly based on personal experience of familial interaction and social activities, thus self-assessment is considered as an outcome variable in this paper. Based on this theoretical groundwork, the framework for this analysis is as shown in Figure 1.

In addition, the pension system in China is characterised by distinct stratification in which pensioners are distributed into four classes in descending order in terms of pension levels but ascending order in terms of coverage. At the top are those in the GIP, in the middle are those covered by the Enterprise Employee Basic Pension (EEBP), followed by those in the Urban and Rural Resident Social Pension (URRSP) and at the bottom are people without any pensions (Zhu and Walker 2017). Disparate and unequal pensions result in distinctly different impacts on social inclusion. For example, nearly half of all urban-dwelling older people have social pensions as their main financial resources compared to only 4 per cent for their counterparts in rural areas. Accordingly, the emerging needs of urban older people are for a rich spiritual and cultural life, keeping pace with the times, social participation and life-long education; while rural older people have to work until an advanced age due to their low incomes (Du 2013). Therefore, it is important to compare the impact of pensions on different classes of older people. 


\section{Huoyun Zhu and Alan Walker}

\section{Data and measurement}

The data-set used in this paper is from a national and longitudinal survey, CLASS, conducted by Renmin University of China in 2014 based on pilot investigations in 2011 and 2012. CLASS aims at regularly collecting information referring to the socio-economic status of older people so as to assess the challenges confronting them and their families as well as the impacts of relevant social policies on promoting the life quality of older people. This survey includes six major sections: demographic characteristics, health status, economic status, supporting resources, living arrangement and social participation. The investigation in 2014 covered almost all provinces in China, with the exception of Hainan, Tibet and Xinjiang, referring to 462 villages/communities from 134 counties/districts with multi-stage probability sampling, and successfully interviewed $11,5^{11}$ older people aged 60 and over. The data are of high quality. For example, the sex ratio of male to female in the survey is 0.9216 , close to the result of the sixth census, $0.975^{6}$, conducted in 2010 (National Survey Research Center at Renmin University of China 2014).

The description of demographic characteristics and pension variables is shown in Table 1. As is usual, the number of women is greater than men, which increases with age group. Also with the economic development of China, urbanisation has increased dramatically over the past three decades. Nearly half of older people were living in urban areas, indicating improved living environments. What stands out initially is the low educational attainment of the majority of older people: over 30 per cent were illiterate and another one-third attained only elementary education, which is likely to affect their attitude to society and consequently to social inclusion.

The independent variable is the pension which was specified as two subvariables: benefit levels and pension types. The former was calculated by the amount of pension benefits per month in 2014; while the later was determined by the three types of pension systems and the last group without any pension. As shown in Table 1, almost 80 per cent of Chinese older people were entitled to pension rights as a result of the unprecedented extension of pensions, with an average annual increase of 19 per cent between 2010 and 2015 (International Social Security Association (ISSA) 2016). Particularly, the New Rural Social Pension piloted in 2009 covered over one-third of older people who were excluded from all pensions before that. Benefit levels among different groups are quite unequal due to the work-test and performance-test pensions. The average pension of the URRSP is only $265.7 \mathrm{CNY}$ per month compared with 2,896 CNY per month for the GIP, a ten-fold difference. 
T A B L E 1. Variables and sample distribution

\begin{tabular}{|c|c|c|c|}
\hline Variables & Values & $\mathrm{N}$ & $\%$ \\
\hline \multirow[t]{2}{*}{ Gender } & Male & 5,528 & 48.0 \\
\hline & Female & 5,983 & $5^{2.0}$ \\
\hline \multirow[t]{3}{*}{ Age } & $6 o-69$ & 5,805 & $5^{0.5}$ \\
\hline & $70-79$ & 3,711 & 32.3 \\
\hline & $80+$ & 1,986 & $17 \cdot 3$ \\
\hline \multirow[t]{2}{*}{ Marital status } & Married & 7,449 & 64.8 \\
\hline & Other & 4,049 & $35 \cdot 2$ \\
\hline \multirow[t]{2}{*}{ Hukou status } & Rural & 5,963 & $5^{1.9}$ \\
\hline & Urban & 5,537 & 48.1 \\
\hline \multirow[t]{4}{*}{ Education } & Illiteracy & 3,617 & 31.4 \\
\hline & Elementary school & 3,877 & $33 \cdot 7$ \\
\hline & Middle and high school & 3,331 & 28.9 \\
\hline & College and above & 679 & 5.9 \\
\hline \multirow[t]{3}{*}{ Health status (activities of daily living) } & Without assistance & 8,311 & 73.0 \\
\hline & Require some help & $1,5^{61}$ & $13 \cdot 7$ \\
\hline & Cannot do without assistance & $1,5^{10}$ & $13 \cdot 3$ \\
\hline \multirow[t]{4}{*}{ Pension type } & GIP & 1,566 & 14.1 \\
\hline & EEBP & $2,5^{14}$ & 22.6 \\
\hline & URRSP & $45^{\circ 6}$ & 40.5 \\
\hline & None & 2,528 & 22.7 \\
\hline \multirow[t]{4}{*}{ Mean pension level (CNY per month) } & GIP & \multicolumn{2}{|c|}{$2,896.4$} \\
\hline & EEBP & \multirow{2}{*}{\multicolumn{2}{|c|}{$\begin{array}{c}2,495 \cdot 9 \\
265.7\end{array}$}} \\
\hline & URRSP & & \\
\hline & All & \multicolumn{2}{|c|}{$1,080.4$} \\
\hline
\end{tabular}

Notes: GIP: Government and Institution Pensions. EEBP: Enterprise Employee Basic Pension. URRSP: Urban and Rural Resident Social Pension.

The dependent variables, familial interaction, social support and public participation, and self-assessment, are latent variables measured by Likert scales or other observed variables. Familial interaction includes income transfers informal service transfers, affective interaction between older people and their children, and living arrangements. Given the diversity of numbers of children and their activities among different families, we used the mean of income transfer and values of informal service transfers and affective interaction provided by the oldest child for the older people with two children and over. The latent variable of social support was measured by a six-point Likert scale with three progressive questions. Public participation consisted of local voting and community activities. The last latent variable, self-assessment, was measured on a five-point Likert scale including four items. All four latent variables and their indicator variables are shown in Table 2. Age, gender, hukou status, education, marital status and occupation before retirement were considered as covariates in the analysis. 


\section{T A B L E 2. Four latent variables and measurement indicators}

\begin{tabular}{|c|c|}
\hline Latent variables & Indicator variables \\
\hline $\begin{array}{l}\text { Familial interaction } \\
\qquad\left(F_{1}\right)\end{array}$ & $\begin{array}{l}\text { F1A: How much was the monetary value of financial transfers from } \\
\text { children to older people in the last } 12 \text { months? F1B: How many } \\
\text { times did children do housework for older people in the last } 12 \\
\text { months? F1C: How many times did children call the older person in } \\
\text { the last } 12 \text { months? F1D: How much was the monetary value of } \\
\text { financial transfers from older people to their adult children in the } \\
\text { last } 12 \text { months? }\end{array}$ \\
\hline Social support (F2) & $\begin{array}{l}\text { F2A: How many friends do you meet or contact with every month? F2B: } \\
\text { How many friends do you talk with about your secrets? F2C: How } \\
\text { many friends will give you help when you need it? }\end{array}$ \\
\hline $\begin{array}{l}\text { Public participation } \\
\qquad\left(\mathrm{F}_{3}\right)\end{array}$ & $\begin{array}{l}\mathrm{F}_{3} \mathrm{~A} \text { : Did you participate in local elections in the past three years? } \mathrm{F}_{3} \mathrm{~B} \text { : } \\
\text { Did you participate in community activities in the past three months? } \\
\mathrm{F}_{3} \mathrm{C} \text { : How many community activities did you participate in during } \\
\text { the past three months? }\end{array}$ \\
\hline Self-assessment $\left(\mathrm{F}_{4}\right)$ & $\begin{array}{l}\mathrm{F}_{4} \mathrm{~A} \text { : I am not old. } \mathrm{F}_{4} \mathrm{~B} \text { : Getting old is not a losing process. } \mathrm{F}_{4} \mathrm{C} \text { : It is not } \\
\text { difficult to make friends when I become an older person. } \mathrm{F}_{4} \mathrm{D} \text { : I am } \\
\text { not excluded from society due to my elder status. }\end{array}$ \\
\hline
\end{tabular}

\section{Methods}

Given the features of latent variables and the theoretical framework, Structural Equation Modelling (SEM) was the most suitable for this analysis. This is a general and broad family of analyses used to test measurement models and to examine the structural models of the relationships among latent variables (Harrington 2008). As for the measurement model, on the one hand, confirmatory factor analysis (CFA) is employed to measure the four latent dependent variables: self-assessment, familial interaction, social support and public participation. CFA, theory-driven analysis, is used for four major purposes: psychometric evaluation of the measures, construct validation, testing method effects and testing measurement invariance (Brown 2006). Compared with exploratory factor analysis, which is data-oriented and is also called data-driven analysis, CFA characterised by hypothesis testing is suitable for the situation where the relationship between latent variables and manifest variables is defined prior to analysis (Wang 2014). In terms of the structural model, on the other hand, the path analysis is as shown in Figure 1. In addition to the direct relationships between pensions and the four latent variables, we attempted to test the mediation role of family, community and society to the sense of subjective social inclusion from the perspective of older people. The software Mplus $7 \cdot 4$ was used. 


\section{Results}

\section{SEM: measurement model}

The measurement model was made up of four latent constructs and 14 manifest variables. Each of the four latent variables was measured by three or four manifest indicators. Given the abnormal distribution of indicators, the maximum likelihood method (MLM) is employed to estimate parameters, which is robust to non-normality (Muthén and Muthén 2015). Results of the analysis suggest good fits, such as self-assessment with chi-square/degrees of freedom of $15^{8.96}$, significant at the 1 per cent level, comparative fit index (CFI) of 0.94 , standardised root mean square residual (SRMR) of o.o4, root mean square error of approximation (RMSEA) of 0.14 ; while the other three latent variables are a saturated model. All loading coefficients are shown in Figure 2. With the exception of income transfers from adult children to their parents and living arrangement in familial interaction, the loading coefficients of all indicators are over 0.5 .

\section{SEM: structural model}

According to the theoretical framework represented above, the tested model is shown in Figure 2, including 14 paths among pensions and latent variables. In this model, we pooled all of the pension types as well as those without pensions whose pension values are zero. Fit indexes indicate an acceptable model with a significant chi-square at the 1 per cent level, CFI of o.94, Tucker-Lewis Index of 0.92, RMSEA of 0.04, as well as SRMR of 0.03.

Although the covariates are removed in order to simplify Figure 2, the full model shows that all control variables are significant for familial interaction. For example, compared to older men, older women are more involved in familial interaction with their children. Meanwhile, older people with a higher degree level of educational attainment, better occupations before retirement and urban household registration have closer relationships with family members than those within lower classes. While the relationships between covariates and the other three dimensions of social inclusion, social support, public participation and self-assessment, show the completely opposite relationship. As for the correlation between pensions and social inclusion, all paths could be divided into nine direct and five indirect ones as shown in Figure 2. In terms of the direct paths, relationships between pensions and familial interaction and self-assessment are positively significant at the 1 per cent level. The coefficient between pensions and public participation is small, revealing that increasing pensions has a small impact on public participation among older people in China. It is 


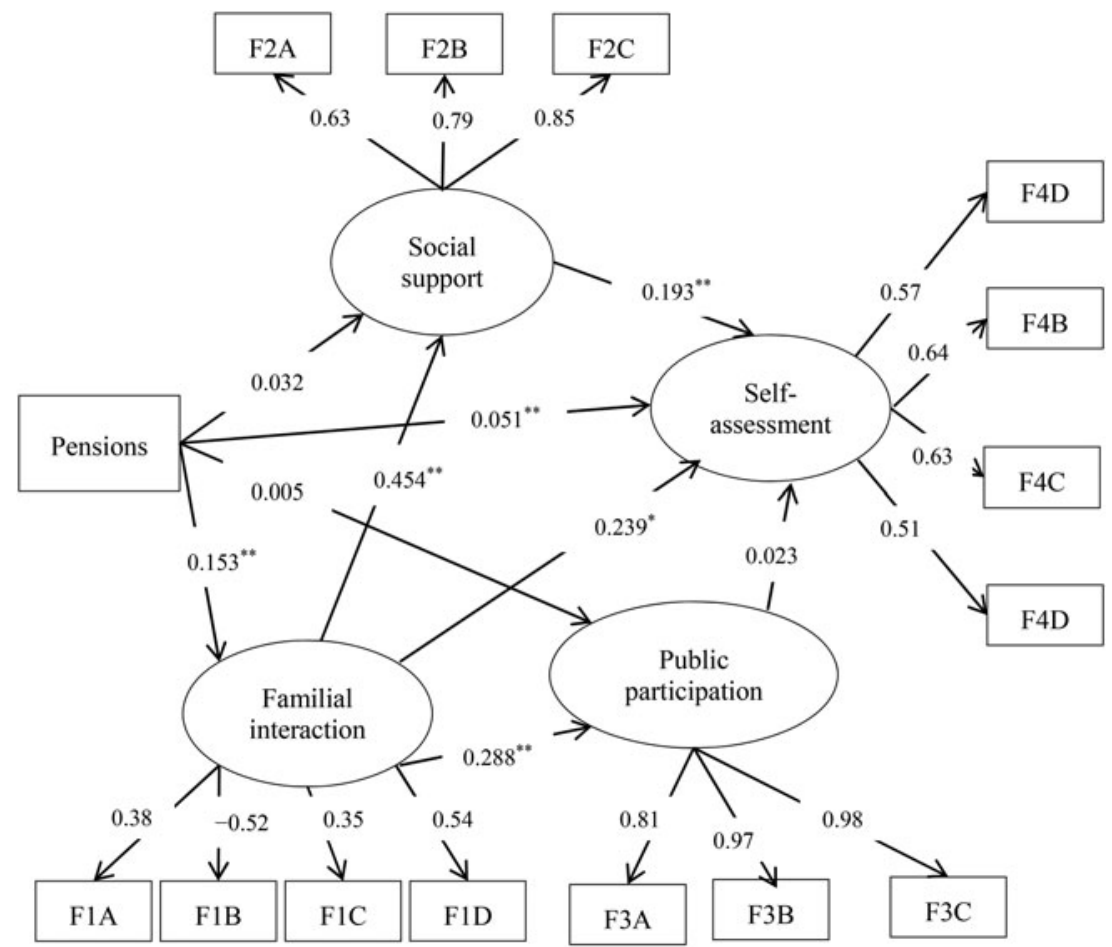

Figure 2. Structural Equation Modelling of the impact of pensions on social inclusion for older people.

Notes: Given high variance of pensions, it is replaced by $\log _{10}^{\text {pension }}$ in the model. F1-F4: see Table 2.

Significance levels: $* p<0.05, * * p<0.01$

surprising that there is no significant association between public participation and the self-assessment of social inclusion, with the control of covariates, the reasons for which will be discussed later.

Referring to the indirect correlations between pensions and social inclusion, the self-assessment of older people is regarded as the comprehensive index of social inclusion, which operates as the terminal variable in the model. The mediation effects of familial interaction and social support are examined with the exception of public participation, again revealing a multi-dimensional social inclusion and interaction between each dimension. The total indirect association coefficient of pensions and self-assessment is 0.043 . Of this, 0.006 and 0.037 are from the mediation effects of social support from friends and familial interaction, which indicates that familial support is more important for the self-assessment of social inclusion than other supports. Being affected by the non-significant correlation 
between public participation and self-assessment, the indirect correlation coefficients of public participation on self-assessment are zero.

As detailed above, three sub-groups of older people were specified according to China's pension system: at the top of the inverted pyramid are those covered by the GIP followed by those retired from enterprises, and at the bottom are older people covered by the URRSP. Before the SEM analysis, bivariate correlation analysis between pensions and four dimensions of social inclusion facilitated a more intuitive understanding of diversity among the sub-groups of older people. Given the categorical variable of pension types, weighted least-square parameter estimates were applied for correlation coefficients. Results show that pension types (GIP $=1, \mathrm{EEBP}=2, \mathrm{URRSP}=3$, none $=4$ ) were significantly negatively correlated with self-assessment $(-0.18)$, social support $(-0.15)$ and public participation $(-0.21)$, with the exception of familial interaction $(0.40)$, at the 1 per cent level, which reveals that older people with better pensions are actually integrated better into society. Surprisingly, however, older people with the lowest pensions have better relationships with their family members than those with higher pensions, which may result from the fact that the poorest are those living in rural areas, being more reliant on their relatives and therefore more likely to be positive.

Specific models with each sub-group categorised by pension types present diversities in detail. Fit indexes and path coefficients of the three models are as shown in Table 3. All fit indexes of the models are acceptable statistically, as argued above. The prominent trend of the three models is the steadily decreasing coefficients between pensions and social inclusion from the GIP model to the URRSP one, although many of them are non-significant at the 5 per cent level. For example, coefficients steadily decrease from 0.471 in the GIP model to 0.287 in the EEBP model and to o.og1 in the URRSP one, as shown in Table 3, which reinforces the conclusion examined above once again that older people with better pensions are more likely to be included into family and society. Only familial interaction out of the four dimensions was significantly positively affected by pensions, at the 1 per cent level in the model of the GIP, which reveals that social inclusion among older people covered by the GIP is not improved along with benefit rises, although they did have higher overall social inclusion than other pension groups. Conversely, older people receiving the EEBP and the URRSP are more sensitive to changes in pension levels. As well as the self-assessment of social inclusion, pensions enable older people covered by the EEBP and the URRSP to feel that they are being included into family, community and society in both direct and indirect ways. However, public participation, which is defined in terms of voting and community activities, is immune to pensions and other dimensions of social inclusion within all of the models. 
T A B L E 3. Comparison of pension impact on social inclusion for sub-groups

\begin{tabular}{|c|c|c|c|c|}
\hline & Index & GIP & EEBP & URRSP \\
\hline \multirow[t]{5}{*}{ Fit indexes } & $\chi^{2}$ & $4^{26.52}$ & 740.05 & 1264.29 \\
\hline & CFI & 0.95 & 0.94 & 0.93 \\
\hline & TLI & 0.93 & $0.9^{2}$ & 0.91 \\
\hline & RMSEA & 0.04 & 0.04 & 0.04 \\
\hline & SRMR & 0.03 & 0.04 & 0.04 \\
\hline \multirow[t]{4}{*}{ Direct path coefficients } & Pensions $\rightarrow \mathrm{F}_{1}$ & $0.417^{* *}$ & $0.287^{*}$ & $0.091 *$ \\
\hline & Pensions $\rightarrow \mathrm{F}_{2}$ & 0.113 & 0.076 & 0.037 \\
\hline & Pensions $\rightarrow \mathrm{F}_{3}$ & 0.147 & 0.013 & 0.023 \\
\hline & Pensions $\rightarrow \mathrm{F}_{4}$ & 0.047 & $0.080^{*}$ & $0.078^{* * *}$ \\
\hline \multirow{5}{*}{$\begin{array}{l}\text { Indirect path } \\
\text { coefficient }\end{array}$} & Pensions $\rightarrow \mathrm{F}_{1} \rightarrow \mathrm{F}_{4}$ & 0.106 & 0.045 & 0.016 \\
\hline & Pensions $\rightarrow \mathrm{F}_{2} \rightarrow \mathrm{F}_{4}$ & 0.019 & 0.014 & 0.007 \\
\hline & Pensions $\rightarrow \mathrm{F}_{3} \rightarrow \mathrm{F}_{4}$ & 0.001 & 0.000 & 0.001 \\
\hline & Pensions $\rightarrow \mathrm{F}_{1} \rightarrow \mathrm{F}_{2} \rightarrow \mathrm{F}_{4}$ & 0.000 & $0.022 * *$ & 0.001 \\
\hline & Pensions $\rightarrow \mathrm{F}_{1} \rightarrow \mathrm{F}_{3} \rightarrow \mathrm{F}_{4}$ & 0.000 & 0.002 & $0.007^{*}$ \\
\hline
\end{tabular}

Notes: GIP: Government and Institution Pensions. EEBP: Enterprise Employee Basic Pension. URRSP: Urban and Rural Resident Social Pension. CFI: comparative fit index. TLI: TuckerLewis Index. RMSEA: root mean square error of approximation. SRMR: standardised root mean square residual. $\mathrm{F}_{1}-\mathrm{F}_{4}$ : see Table 2.

Significance levels: $* p<0.05, * * p<0.01$.

\section{Discussion}

Of particular relevance in developing countries is a focus on issues around material and financial security, which reflects the income resources domain of both social exclusion and social inclusion frameworks (Burchardt, Le Grand and Piachaud 2002; Scharf and Keating 2012; Scharf, Phillipson and Smith 2005). As the former president of the ISSA said when he presented the second ISSA Award for outstanding achievement in 2016 to the Chinese government, 'China has made unprecedented progress in the development of its social security system in the past decade and has successfully extended pension, health and other forms of coverage for the benefit of its population through a combination of sustained government commitment and significant administrative innovations'. As a major yet still middle-income country, China has made substantial efforts to extend pension coverage by the use of non-contributory pensions (e.g. the URRSP) in the past decade. The majority of social surveys indicate that the coverage rate of pensions has reached around 80 per cent. Benefit levels are also increasing along with economic development. The levels of the EEBP have increased at a rate of 10 per cent every year since 2005 and 8 per cent in 2016, the amount of pensions per month on average has increased from $711 \mathrm{CNY}$ in 2004 to 2,353 CNY in 2015 (Ministry of Human Resources and Social Security 2015). Income transfers among 
family members, labour income and pensions are three major income resources among older people in China. Although income transfers from children still comprise more than 40 per cent of income, it was 57 per cent in 1994 and has steadily decreased since then ( $\mathrm{Du}$ and $\mathrm{Wu}$ 2006), while the percentage of pensions has increased from 15.6 per cent in 1994 to 24.1 per cent in 2010 (Ding 2013), and resulted in substantial poverty reduction among older people.

The focus of this paper, however, is not on the economic impact of pensions but their impact on social relations and subjective attitudes towards social inclusion among older adults. Beyond increasing their income, there is a range of ways in which increased pensions boost older people's social inclusion. At the individual level increased pensions provide an income replacement in retirement, therefore their relative generosity positively affects the wellbeing and life satisfaction of older people. Also the importance of relative income in the determination of life satisfaction is also true for pensions (Bender 2004). However, in the model without the control variable 'occupation before retirement', a direct correlation between material pension welfare and self-assessment of social inclusion was not found in the model pooled total sample, but was found in the sub-models categorised by pension types and in the model with 'occupation before retirement'. As suggested above, selfassessment is a comprehensive index produced by older people based on personal experiences and their living environment, which are affected by multiple factors rather than only pensions. Similar to the subjective satisfaction index, one reason for its lack of influence is that expressed satisfaction with a particular performance may not be affected by any characteristics of that performance (Stipak 1979). Subjective assessment of public services was examined as a function of neighbourhood, individual and governmental characteristics and their social relationships (Stipak 1976). As stated in this paper, pensions have no impact on selfassessment when covariates are considered, but they do have an impact on it within sub-models and, in particular, the model with occupation before retirement which to a large extent determines who gets which pensions (Zhu and Walker 2017). This indicates differences of selfassessment among social groups categorised by individual, occupational, economic and social factors. Also the statistically significant mediation effects of familial interaction and social support between pensions and self-assessment inclusion suggest a way to improve subjective social inclusion. Increasing pensions, especially for older people living in rural areas and those without any pensions at present, can improve their social capital, familial relationships and therefore their subjective wellbeing. 


\section{$135^{2}$ Huoyun Zhu and Alan Walker}

The relationship between pensions and familial interaction is more complex. An important finding is that increased pensions enhance the interaction between older people and their adult children in terms of income transfers and verbal communication, but have a negative effect on service interaction, as shown in Figure 2 (a negative loading coefficient of $F_{1} B$ on $F_{1}$ ). Although affected by socio-economic change characterised by economic growth, high-speed population mobility and smaller family structure, familial relationships with a 'feedback model' in essence remain unchanged in China (Fei 1983). A survey in Shenzhen, the largest immigrant city in China, indicated that the majority of immigrants $(67.7 \%)$ expressed a close relationship with their parents even though they live far apart from them (Cui and Jin 2015). Although constrained by geographical distance, income and emotional interactions remain close regardless of the health status of the parents. Thus, familial interactions without spatial-temporal limits such as income transfers and telephone calls are strengthened, while service interactions are inevitably weakened. From the perspective of older people, increased pension income not only reduces their dependence on their children and friends, but also enables them to help others. Recognition and respect from children as a result of supporting and sustaining their family with pensions contribute to the positive assessment of intra-household relationships from the perspective of older people (Lloyd-Sherlock, Barrientos and Mase $2012)$.

Based on the Asian cultural background, social participation provides new role identities for older adults in the context of the erosion of traditional family ones (Warburton and Wintertion 2010). Taking part in community activities is regarded as a continuation of the role of family leaders as the breadwinners and carers, which totally disappear when they retire $(\mathrm{Mu} 2002)$. However, social participation seems to be immune to both financial income and other social relations, as we have shown, although it is an important path to social inclusion for older people from the perspective of active ageing in which older people are given opportunities to develop their own forms of activity as citizens (Walker 2002). The factors are multiple relating to older people and their families as well as the government rather than focusing on material income (Wang 2011). Firstly, health and volition are two key factors determining social participation at the individual level. When asked the reason for the absence of community activities, poor health and without interest were the first and third reasons, consisting of 27.6 and 11.1 per cent, respectively. Secondly, the traditional culture poses another important barrier for older people to engage in social participation. The concept of 'structure of grade' ( $\operatorname{ch} x u$ ge ju), put forward by Fei Xiaotong, based 
on Confucianism, takes the family as the centre of a social network surrounded by relatives and followed by those without blood relationships such as friends and colleagues, and strangers are last (Fei 1992). This suggests that older people are expected to spend time with their families and undertake responsibilities defined by culture, such as caring for grandchildren and doing domestic work, before taking part in community activities. One of the factors behind absence from social participation in this survey is the family, including caring for other family members and opposition from their children, which makes up of 6.4 per cent. Thirdly, the lack of infrastructure contributes another important factor behind limited social participation. As many as 18.1 per cent of respondents in this survey gave the reason for their lack of social participation as not knowing how to take part, even though they had the desire to. Ageism, regarding old age as a disability and, consequently, regarding older people as the objective of services rather than as carers or active citizens, is prevalent as a result of ignorance. Thus legislation, social organisations, funding, human resources and so on supporting community activities are completely absent (Han 2007; Liu 2006).

In addition to inequalities in pension income among individuals and households, the impact of pension stratification, in the form of three public pension schemes, reflects a complex and hierarchical relationship between pensions and social inclusion at the macro-social level (Calvo 2009). Pension policies are embedded in structural and cultural circumstances that mediate how people respond to those policies. Older people being part of a well-designed pension system, such as the GIP, with better pensions on average, are those with advantages in their previous lifecourse. They are still at the lowest risk of social exclusion even if pensions are not taken into consideration. The impact of pensions on social inclusion is not only about the amount of the pension, but also about those living with a high degree of risk in a world where basic material needs have not been met. Better pensions have a weak impact on social inclusion for older people covered by the GIP, but they have a higher degree of social inclusion than other pension classes. In contrast, social inclusion for older people in the EEBP and the URRSP are more sensitive to pension level. The inequality of pensions with performance-tests and work-tests has an adverse impact on the relationship between financial income and social inclusion. Older people with disadvantages over the lifecourse are more likely to be excluded from family, friends and community, as well as in terms of the psychological feelings about themselves, as the result of extremely low pensions, although they are the ones with the most urgent need of decent pensions, which are the major source of resources to compensate for their disadvantages. 


\section{Conclusion}

Social exclusion and inclusion are discussed in the western arenas of gerontology and social policy but are largely absent from similar discussions in developing countries and particularly in China. Accompanied by economic transition, more social policies referring to inclusive development indicate a paradigm shift from an economy-oriented development model to an economy and society-oriented model. In accordance with other developing countries, the pension system is one of a few vital social policies responding to the social exclusion of older people in China and their need for inclusion. This paper provides a uniquely comprehensive exploration of the relationship between pensions and social inclusion using highly reliable nation-wide survey data, the results of which provide valuable information for future reforms both in China and other developing countries. On the one hand, pension policy should take priority over any other measures as an instrument to achieve social inclusion among older people in developing countries. In addition to substantial poverty reduction, an important dimension of social inclusion, pension income promotes familial interaction, social support and community participation, and results in positive subjective assessments of integration in society among older people. On the other hand, however, equality-oriented pensions which aim to reduce disadvantages from the previous lifecourse are effective at offsetting or eliminating huge inequalities deriving from the labour market, family and social welfare systems. The potential of pensions as an engine of social inclusion among older people in China is currently limited by its stratified pension system. Finally, infrastructure such as activity spaces, volunteer organisations, funding and social motivators should also be provided to co-ordinate with pension policy, which is rather rare in developing countries.

\section{Acknowledgements}

The authors would like to thank the anonymous reviewers for their helpful comments and Vanessa Rodgers for her support in the publication process.

\section{References}

Arber, S. and Ginn, J. 1991. Gender and Later Life. Sage, London.

Barrientos, A. 2015. Is there a role for social pensions in Asia? Asia and the Pacific Policy Studies, 2, 1, 8-20. 
Barrs, J., Dannefer, D., Phillipson, C. and Walker, A. 2006. Ageing, Globalisation and Inequality. New York.

Bello, H., Letete, H. M., Rapapa, N. P. and Chakobane, L. 20o8. An evaluation of the poverty reduction impact of the non-contributory old age pension programme in Lesotho: the case of Manonyane. Review of Southern African Studies Journal, 12, 1/2, $76-106$.

Bender, K. A. 2004. The Well-being of Retirements: Evidence Using Subjective Data. Center for Retirement Research at Boston College, Boston.

Bender, K. A. 2012. An analysis of well-being in retirement: the role of pensions, health, and 'voluntariness' of retirement. Journal of Socio-economics, 44, 4, 424-33.

Bertranou, F. and Grushka, C. O. 2002. The non-contributory pension programme in Argentina: assessment of the impact on poverty reduction. ESS Paper 5, International Labour Organization, Geneva.

Bertranou, F., Van Ginneken, W. and Solorio, C. 2004. The impact of tax-financed pensions on poverty reduction in Latin America: evidence from Argentina, Brazil, Chile, Costa Rica and Uruguay. International Social Security Review, 57, 4, 3-18.

Brocklehurst, H. and Laurenson, M. 2008. A concept analysis examining the vulnerability of older people. British Journal of Nursing, 17, $21,1354^{-7}$.

Brown, T. A. 2006. Confirmatory Factor Analysis for Applied Research. Guilford Press, New York.

Buffel, T., Phillipson, C. and Scharf, T. 2013. Experiences of neighbourhood exclusion and inclusion among older people living in deprived inner-city areas in Belgium and England. Ageing E Society, 33, 1, 89-109.

Burchardt, T., Le Grand, J. and Piachaud, D. 2002. Degrees of exclusion: developing a dynamic multidimensional measure. In Hills, J., Le Grand, J. and Piachaud, D. (eds), Understanding Social Exclusion. Oxford University Press, Oxford, 30-43.

Burns, V.F., Lavoie, J.P. and Rose, D. 201 2. Revisiting the role of neighbourhood change in social exclusion and inclusion of older people. Journal of Ageing Research, 2012, 1-12.

Byrne, D. 2005. Social Exclusion. Second edition, Open University Press, Maidenhead, UK.

Calvo, E. 2009. The Impact of Pension Policy on Older Adults' Life Satisfaction: An Analysis of Longitudinal Multilevel Data. Boston College, Boston.

Chen, S. 1999. An analysis of living resources of older person reserved by themselves. Population Journal, 5, 1 7-23.

Copestake, J. and Camfield, L. 2010. Measuring multidimensional aspiration gaps: a means to understanding cultural aspects of poverty. Development Policy Review, 28, 5, 617-33.

Cribb, J., Hood, A., Joyce, R. and Phillips, D. 2013. Living Standards, Poverty and Inequality in the UK: 2013. The Institute for Fiscal Studies, London.

Cui, Y. and Jin, X. 2015. Intergenerational relationship in migrant families in the context of rural to urban migration: a typological analysis. Population Research, 39, 3, 48-6o.

Cumming, E. and Henry, W. 1961. Growing Old: The Process of Disengagement. Basic Books, New York.

Dannefer, D. 2003. Cumulative advantage/disadvantage and the life course: crossfertilizing age and social science theory. Journals of Gerontology: Social Sciences, $\mathbf{5 8 B}, 6, \mathrm{~S}_{327}-37$.

Dhemba, J. 2013. Overcoming poverty in old age: social security provision in Lesotho, South Africa and Zimbabwe revisited. International Social Work, 56, 6, 816-27. 
Diener, E., Tay, L. and Oishi, S. 2012 . Rising income and the subjective well-being of nations. Journal of Personality and Social Psychology, 104, 2, 267-76.

Ding, Z. 2013. The change of income sources in China old people: 2005-2010. Population Journal, 35, 1, 69-77.

Du, P. 2013. Intergenerational solidarity and old-age support for the social inclusion of elders in Mainland China: the changing roles of family and government. Ageing E Society, 33, 1, 44-63.

$\mathrm{Du}, \mathrm{P}$. and $\mathrm{Wu}, \mathrm{C}$. 2006. The change of income sources in China old people: 19942004. Population Research, 3o, 2, 20-4.

Easterlin, R.A. 2010. Happiness, Growth and the Life Cycle. Oxford University Press, Oxford.

Esser, I. and Palme, J. 2010. Do public pensions matter for health and wellbeing among retired persons? Basic and income security pensions across 13 western European countries. International Journal of Social Welfare, 19, $\mathrm{S} 1,103^{-20}$.

Fei, X. 1983 . Support for older people in the process of family structure change: revision of family structure change of China. Journal of Peking University (Philosophy and Social Sciences), 3, 6-15.

Fei, X. 1992. From the Soil: The Foundations of Chinese Society: A Translation of Fei Xiaotong 'Xiangtu Zhongguo'. University of California Press, London.

Feng, W. M. 2011 . Social exclusion of the elderly in contemporary China: one empirical study based on the surveys in six provinces. Revised Organisation for Economic Co-operation and Development paper. Organisation for Economic Co-operation and Development, Paris.

Fontenot, K. R., Renwick, T.J. and Housing Statistics Division. 2016. Poverty by Age and Sex: An Examination of the Distribution in Poverty Between I966 and 2014. Census Bureau, Washington DC.

Gao, C. 2012. On theoretic core of inclusive growth. Journal of Nanjing University (Philosophy, Humanities and Social Sciences), 1, 32-9.

Gupta, J., Pouw, N. R. M. and Ros-Tonen, M.A. F. 2015. Towards an elaborated theory of inclusive development. European Journal of Development Research, 27, 4, $54^{1-59}$.

Han, Q. 2007. Situation, problems and polices relating to social participation of older people. Journal of Nanjing College for Population Programme Management, 23, 4, 41-4.

Handayani, S. W. and Babajanian, B. 2012. Social Protection for Older Persons: Social Pensions in Asia. Asian Development Bank, Philippines.

Harrington, D. 2008. Confirmatory Factor Analysis. Oxford University Press, Oxford.

HelpAge International 200o. The Mark of a Noble Society. HelpAge International, London.

International Labour Organization 2014. World Social Protection Report 2014/I5: Building Economic Recovery, Inclusive Development and Social Justice. International Labour Organization, Geneva.

International Social Security Association (ISSA) 2016. Government of China Receives International Social Security Award. World Social Security Forum, Panama.

Jehoel-Gijsbers, G. and Vrooman, C. 2007. Explaining Social Exclusion: A Theoretical Model Explaining Social Exclusion Tested in the Netherlands. The Netherlands Institute for Social Research/CP, The Hague.

Kakwani, N. and Subbarao, K. 2007. Poverty among the elderly in Sub-Saharan Africa and the role of social pensions. Journal of Development Studies, 43, 6, 987-10o8.

Kangas, O. 2010. One hundred years of money, welfare and death: mortality, economic growth and the development of the welfare state in 17 OECD countries 1900-2000. International Journal of Social Welfare, 19, $\mathrm{S}_{1}, 4^{2-59}$.

Lancet, T. 2016. Ageing in China: a ticking bomb, Lancet, 388, $10056,205^{8 .}$ 
Levitas, R., Pantazis, C. and Fahmy, E. 2007. The Multi-dimensional Analysis of Social Exclusion. Social Exclusion Unit, Cabinet Office, London.

Li, B., Zhang, H. and Chen, Y. 2015. Institutionalization of basic services for elderly: theoretical analysis and policy framework. Population Research, 39, 2, 91-9.

Li, Y. and Zhang, X. 2014. New norms and Chinese economy's new birth. China Opening Journal, 6, 19-22.

Liu, S. 2006. Difficulties and policies referring to social participation of older people from the perspective of active ageing. Journal of Nanjing College for Population Programme Management, 22, 4, 5-9.

Lloyd-Sherlock, P. 2010. Population Ageing and International Development: From Generalisation to Evidence. Policy Press, Bristol, UK.

Lloyd-Sherlock, P., Barrientos, A. and Mase, J. 2012. Social inclusion of older people in developing countries: relations and resources. In Scharf, T. and Keating, N. C. (eds), From Exclusion to Inclusion in Old Age: A Global Challenge. Policy Press, Bristol, $\mathrm{UK}, 5^{1-70}$.

Lloyd-Sherlock, P., Saboia, J. and Ramírez-Rodríguez, B. 201 2. Cash transfers and the well-being of older people in Brazil. Development and Change, 43, 5, 1049-72.

Lui, C., Warburton, J., Wintertion, R. and Barlett, H. 201 1. Critical reflections on a social inclusion approach for an ageing Australia. Australian Social Work, 64, 3, 266-82.

Ministry of Human Resources and Social Security 2015. Report of the Ministry of Human Resources and Social Security 2015. Ministry of Human Resources and Social Security, Beijing.

$\mathrm{Mu}, \mathrm{G}$. 2002. Ageing development: basic framework of successful ageing strategy in 21 st century. Population Research, 26, 6, 29-37.

Muthén, L. K. and Muthén, B. O. 2015. Mplus Users's Guide. Seventh edition, Muthén \& Muthén, Los Angeles.

National Survey Research Center at Renmin University of China 2014. China Longitudinal Aging Social Survey Report 2014. National Survey Research Center at Renmin University of China, Beijing.

Nazroo, J., Bajekal, M., Blane, D. and Grewal, I. 2004. Ethnic inequalities. In Walker, A. and Hagen Hennessy, C. (eds), Growing Older. Open University Press, Maidenhead, UK, $35^{-59}$.

Norström, T. and Palme, J. 201 o. Public pension institutions and old-age mortality in a comparative perspective. International Journal of Social Welfare, 19, S1, $121-30$.

O'Rand, A. 2002. Cumulative advantage theory in life course research. Annual Review of Gerontology and Geriatrics, 22,1, $14^{-20 .}$

Okulicz-Kozaryn, A. 201 2. Income and well-being across European provinces. Social Indicators Research, 106, 2, 371-92.

Panis, C. W. A. 2004. Annuities and retirement well-being. In Mitchell, O. S. and Utkus, S.P. (eds), Pension Design and Structure: New Lessons from Behavioral Finance. Oxford University Press, Oxford, 1-26.

Pestieau, P., Dethier, J. and Ali, R. 2011 . The impact of a minimum pension on old age poverty and its budgetary cost. Evidence from Latin America. Revista de Economicia del Rosario, 14, 2, $135^{-63}$.

Phillipson, C. and Scharf, T. 2004. The Impact of Government Policy on Social Exclusion Among Older People. Office of the Deputy Prime Minister, London.

Price, D., Glaser, K., Ginn, J. and Nicholls, M. 2016. How important are state transfers for reducting poverty rates in later life? Ageing $\mathcal{E}$ Society, 36, 9, 1794-825.

Rauniyar, G. and Kanbur, R. 2010. Inclusive growth and inclusive development: a review and synthesis of Asian Development Bank literature. Journal of the Asia Pacific Economy, 15, 4, 455-69. 


\section{$135^{8}$ Huoyun Zhu and Alan Walker}

Scharf, T. and Keating, N. C. (eds) 2012. From Exclusion to Inclusion in Old Age: A Global Challenge. Policy Press, Bristol, UK.

Scharf, T., Phillipson, C. and Smith, A. E. 2005. Social exclusion of older people in deprived urban communities in England. European Journal of Ageing, 2, 2, 76-87.

Scharlach, A. and Lehning, A. J. 2013. Ageing-friendly communities and social inclusion in the United States of America. Ageing E् Society, 33, 1, 110-36.

Silver, H. 1994. Social exclusion and social solidarity: three paradigms. International Labour Review, 133, 5/6, 531-78.

Social Exclusion Unit 2006. A Sure Start to Later Life: Ending Inequalities for Older People. Office of the Deputy Prime Minister, London.

Stipak, B. 1976 . Are there sensible ways to analyze and use subjective indicators of urban service quality? Social Indicator Research, 6, 4, 42 1-38.

Stipak, B. 1979. Citizen evaluations of urban services as performance indicators in local policy analysis. PhD dissertation, University of California, Los Angeles.

Suwanrada, W. and Wesumperuma, D. 2012. Development of the old-age-allowance system in Thailand: challenges and policy implications. In Handayani, S. W. and Babajanian, B. (eds), Social Protection for Older Persons: Social Pensions in Asia. Asian Development Bank, Philippines, ${ }^{5} 53-67$.

Titmuss, R. M. 1955. Pension systems and population change. Political Quarterly, 26, $2,15^{2-66 .}$

Townsend, P. 1981. The structured dependency of the elderly: a creation of social policy in the twentieth century. Ageing E Society, 1, 1, 5-28.

United Nations 201 2. World Population Prospects: The 2012 Revision. CD-ROM edition, Department of Economic and Social Affairs, New York.

United Nations 2013. World Population Ageing 2013. Department of Economic and Social Affairs, New York.

Walker, A. 1980. The social creation of poverty and dependency in old age. Journal of Social Policy, 9, 1, 49-75.

Walker, A. 1981. Toward a political economy of old age. Ageing E Society, 1, 1, 73-94.

Walker, A. 2002. A strategy for active ageing. International Social Security Review, 55, 1 , $121-39$.

Walker, A. 2oog. Why is Ageing so Unequal?. In Cann, P. and Dean, M. (eds) Unequal Ageing. Policy Press, Bristol, 159-72.

Walker, A., Barnes, M., Blom, A., Cox, K. and Lessof, C. 20o6. The Social Exclusion of Older People: Evidence from the First Wave of the English Longitudinal Study of Ageing (ELSA). Office of the Deputy Prime Minister, London.

Walker, A., Sinfield, A. and Walker, C. 201 1. Fighting Poverty, Inequality and Injustice: A Manifesto Inspired by Peter Townsend. Policy Press, Bristol, UK.

Walker, A. and Walker, C. 1997. Britain Divided: The Growth of Social Exclusion in the I980s and I990s. Children Poverty Action Group, London.

Walker, A. and Walker, C. 2012. Social Inclusion. In Van der Maesen, L. and Walker, A. (eds) Social Quality:From Theory to Indicators. Palgrave, Houndmills, $173-97$.

Wang, L. 2011 . Literature review of theory, empirical study and policy referring to old age participation in China. Population and Development, 17, 3, 35-43.

Wang, M. 2014. Latent Variable Modeling Using Mplus. Chongqing University Press, Chongqing, China.

Warburton, J., Ng, S. H. and Shardlow, S. M. 2013. Social inclusion in an ageing world: introduction to the special issue. Ageing $\mathcal{E}$ Society, 33, 1, 1-15.

Warburton, J. and Wintertion, R. 2010. The role of volunteering in an era of cultural transition: can it provide a role identity for older people from Asian cultures? Diversity, 2, 8, $104{ }^{8-} 5^{8}$. 
Pensions and social inclusion in an ageing China 1359

World Health Organization (WHO) 2002. Active Ageing: A Policy Framework. WHO, Madrid.

Xiang, Z. 2014. Chinese economy steps into 'new normal'. China Policy Review, 6, 23-6. Zaidi, A. and Antczak, R. 2016. Risk of poverty among older people in EU countries. CESifo DICE Report, 1, 36-46.

Zhu, H. and Walker, A. 2017 . Pension system reform in China: who gets what pensions. Social Policy Eं Administration, 1-15. https://doi.org/10.1 11/spol.1 2368.

Accepted zo November 2017 ; first published online 6 June 2018

Address for correspondence:

Alan Walker,

Department of Sociological Studies,

The University of Sheffield, Elmfield,

Northumberland Road, Sheffield Sio 2TU, UK

E-mail: a.c.walker@shefffield.ac.uk 